\title{
Alcohol use among sexual minority women: Methods used and lessons learned in the 20-Year Chicago Health and Life Experiences of Women Study
}

\author{
Tonda L. Hughes $\oplus^{1}$, Sharon C. Wilsnack $\oplus^{2}$, Kelly Martin ${ }^{1}$, Alicia (Phoenix) Matthews $\circledast^{3}$, and Timothy P. \\ Johnson $\oplus^{4}$ \\ ${ }^{1}$ School of Nursing and Department of Psychiatry, Columbia University \\ ${ }^{2}$ Department of Psychiatry and Behavioral Science, University of North Dakota School of Medicine \& Health Sciences \\ ${ }^{3}$ Population Health Nursing Sciences, University of Illinois at Chicago \\ ${ }^{4}$ Center for Clinical and Translational Science, University of Illinois at Chicago
}

\begin{abstract}
Background: Two decades ago, there was almost no research on alcohol use among sexual minority women (SMW, e.g., lesbian, bisexual). Since then, a growing body of scientific literature documents substantial sexual orientation-related disparities in alcohol use and alcohol-related problems. Research has identified multiple risk factors associated with high-risk/hazardous drinking among SMW. However, this research has almost exclusively used cross-sectional designs, limiting the ability to draw conclusions about processes through which sexual minority status affects alcohol use. Longitudinal designs, although very rare in research on alcohol use among SMW, are important for testing mediational mechanisms and necessary to understanding how changes in social determinants impact alcohol use.
\end{abstract}

Aim: To describe the processes and lessons learned in conducting a 20-year longitudinal study focused on alcohol use among SMW.

Methods: The Chicago Health and Life Experiences of Women (CHLEW) study includes five waves of data collection (2000present) with an age and racially/ethnically diverse sample of 815 SMW (ages 18-83) originally recruited in the Chicago Metropolitan Area in Illinois, a midwestern state in the United States (U.S.). Measures and focus have evolved over the course of the study.

Results: The CHLEW study is the longest-running and most comprehensive study of SMW's drinking in the U.S. or elsewhere. Findings reported in more than 50 published manuscripts have contributed to understanding variations in SMW's risk for hazardous/harmful drinking based on sexual identity, age, race/ethnicity, sex/gender of partner, and many other factors.

Conclusions: By describing the process used in conducting this long-term study, its major findings, and the lessons learned, we hope to encourage and support other researchers in conducting longitudinal research focused on SMW's health. Such research is critically important in understanding and ultimately eliminating sexual orientation-related health disparities.

\section{Introduction}

The Chicago Health and Life Experiences of Women (CHLEW) is the longest running, most comprehensive study of sexual minority women's (SMW, e.g., lesbian, bisexual) drinking and health worldwide. The CHLEW was initiated in the 1990s to address major gaps in the research literature.
Despite limited scientific evidence, in the 1980s and 1990s heavy drinking and drinking-related problems were viewed as prevalent among lesbian women (Finnegan \& McNally, 1990; McKirnan \& Peterson, 1989; Skinner, 1994). Although alcohol research among women in the general population increased dramatically during that time (Brady et al., 2009; Wilsnack \& Wilsnack, 2013), lesbian women were largely ignored (Hughes \& Wilsnack, 1994, 1997; Hughes et al., 2007a, 2007b, 2016). Epidemiologic studies of alcohol use rarely assessed sexual orientation, and sexual minority

Correspondence: Tonda L. Hughes at Columbia University, School of Nursing, Room 609, 560 West 168th Street, New York, NY 10032.

Email: th2696@cumc.columbia.edu

Financial support: The authors would like to acknowledge the support of the National Institute on Alcohol Abuse and Alcoholism (K01AA00266; R01AA013328-14, 2R01AA013328-6S1 and Office of Women's Health Research (ORWH) R56 to bridge R01AA013328-10, Hughes PI). The content is solely the responsibility of the authors and does not necessarily represent the official views of the National Institutes of Health.

Declaration of interest: None

Keywords: sexual minority women, lesbian, bisexual, alcohol use, longitudinal research 
(SM) health surveys seldom assessed alcohol use. Although the AIDS crisis stimulated research on substance use among men who have sex with men (Hughes \& Eliason, 2002; Institute of Medicine [IOM], 2011), few studies explored alcohol use among lesbian women or risk and protective factors associated with SMW's hazardous drinking (HD): a pattern of alcohol use that increases risk of harmful consequences (World Health Organization, 1994). Early studies of lesbian women's drinking were limited by many methodological problems including small nonrepresentative samples, lack of appropriate control/comparison groups, and inconsistent definitions of sexual orientation (IOM \& Solarz, 1999).

\section{Lesbian Women's Use of Alcohol}

In the late 1990s and early 2000s researchers began using existing national data sets to estimate HD prevalence among lesbian women (Cochran \& Mays, 2000; Gilman et al., 2001; Sandfort et al., 2001; Valanis et al., 2000). However, these studies used sexual behavior as a proxy for lesbian identity. The researchers found higher rates of current drinking, heavy drinking, and/or alcohol dependence symptoms among women who reported having had female partners than those reporting only male partners.

Beyond general agreement that lesbian women were at heightened risk for alcohol-related problems, few studies examined factors contributing to HD among lesbian women (Bloomfield, 1993; Heffernan, 1998; McKirnan \& Peterson, 1989; Parks, 1999). Those studies that did, found that "cultural vulnerability" factors (e.g., bar orientation, drinking norms, minority stress) did not fully explain differences between lesbian and heterosexual women.

In 1997 a U.S. Institute of Medicine committee was convened to study lesbian health research. The committee's report (IOM \& Solarz, 1999) highlighted large knowledge gaps and emphasized the need for longitudinal research to better understand the physical and mental health of lesbian women; substance abuse was highlighted as a key health issue. It was within this context that the CHLEW study was designed.

\section{Methods}

\section{Study Design}

The purpose of the baseline CHLEW (1999-2002) was to examine risk and protective factors for heavy drinking and drinking-related problems among lesbian-identified women. Following IOM recommendations, the study aimed to improve upon previous research by including a more diverse and representative sample and an appropriate comparison group, using a well-tested questionnaire, and collecting contact information to facilitate follow-up.

We designed CHLEW to replicate and extend the National Study of Health and Life Experiences of Women (NSHLEW), a 20-year longitudinal study (1981, 1986, 1991, 1996,2001 ) of more than 1600 women in the U.S. general population (Wilsnack et al., 1984, 1991, 1998). Using the same measures in both studies allowed us to use age- matched urban and suburban women from the NSHLEW as a comparison group in the first two waves of CHLEW.

CHLEW Wave 2 was funded in 2002 (2002-2007) and aimed to compare patterns of drinking (drinking levels, heavy episodic drinking [HED], intoxication), drinking consequences, and alcohol dependence symptoms in lesbian versus heterosexual women across age and racial/ethnic groups, and to examine changes in drinking patterns (and predictors of change) between data collected in Wave 1 and Wave 2.

In Wave 3 (2009-2015) we used cross-sectional and longitudinal data to model effects of cumulative stress on HD. Our research has shown that SMW's vulnerability begins with early risk factors, especially childhood sexual abuse (CSA; Hughes et al., 2001; Hughes et al., 2007), and continues with adult sexual or physical victimization (Hughes et al., 2001, 2010a, 2010b, 2014). SMW also experience chronic SM-related stressors, such as prejudice and discrimination. Wave 3 aimed to study the cumulative effects of multiple stressors on mental health (Pearlin et al., 2005) and understand how these stressors may result in HD as a coping mechanism (Johnson et al., 2013).

Waves 4 and 5 of the CHLEW (2016-2022) were designed to evaluate the impact of legalization of same-sex marriage on SMW's drinking and health and to examine the associations of long-term drinking trajectories with SMW's health (Wave 5 is currently in progress and we are just beginning to analyze data from Wave 4).

\section{Study Instrument}

In the NSHLEW, women's drinking patterns and consequences were posited to result from the direct and indirect effects of five sets of influences: (a) origins, upbringing, and early life experiences; (b) adult life experiences; (c) personality characteristics; (d) roles and relationships; and (e) expectancies about alcohol's effects. We considered these important in understanding lesbian women's drinking, but speculated some would operate differently (e.g., variables related to marriage/committed relationships). We also recognized the importance of including factors unique to lesbian women's lives and experiences.

The NSHLEW survey was designed in cooperation with the University of Chicago's National Opinion Research Center (NORC). The 80-page questionnaire included nearly 400 initial questions, with multiple follow-up questions for positive responses that permitted in-depth assessments of many early and later risk factors associated with women's drinking (Wilsnack \& Wilsnack, 1995; Wilsnack, 1991). Measures used in the NSHLEW were selected, whenever possible, from instruments validated in previous research. The NSHLEW questionnaire was refined over time to retain measures with the highest reliability and validity. Questions were designed to maximize women's comfort and valid selfreporting of potentially sensitive behaviors. Interviewer probes were worded to avoid stigmatization of heavy drinking, and self-administered handouts (with privacy 
envelopes) were used for sensitive questions such as adult sexual behaviors.

We closely replicated the NSHLEW instrument to allow comparisons between heterosexual women in the general population and lesbian women in CHLEW. In early 1996, we worked with NORC staff to conduct two pretests of the survey, in part to determine whether self- or intervieweradministration was more effective. In one session eight SMW were interviewed by NORC interviewers; seven others responded using a self-administered questionnaire. All 15 SMW then participated in one of two focus group interviews. The interviewer-administered method was preferred and more reliable than the self-administered method (Hughes et al., 2005). Based on pretest and focus group results, we added or revised several questions, including sexual orientation questions, to be more inclusive of lesbian women's experiences. These changes were also incorporated in NSHLEW Wave 5 (2001). Populationspecific questions, such as sexual identity development benchmarks and sexual identity disclosure, were added to CHLEW. We conducted a full-scale pre-test in 1997-98 with 63 lesbian and 57 heterosexual women (Hughes et al., 2003, 2005; Hughes et al., 2001). We have conducted more limited pretests prior to each wave of the CHLEW study.

\section{Study Measures}

Across waves we dropped measures that had not proven useful. However, to permit longitudinal comparisons, we retained most drinking measures and measures of key risk and protective factors.

\section{Sexual Orientation}

In the late 1990s, health researchers were just beginning to consider sexual orientation an important variable (Sell \& Becker, 2001). Like race/ethnicity and socioeconomic status (SES), sexual orientation is a complex constructcommonly defined as including behavioral, affective (attraction or desire), and cognitive (identity) dimensions. Although these dimensions are generally strongly correlated, they are not perfectly congruent (Geary et al., 2018; Talley et al., 2015). For example, women who have had same-sex partners do not uniformly identify as lesbian, and those who do may have both female and male sexual partners or not be sexually active.

The choice of which dimension(s) of sexual orientation to measure depends on the study purpose (IOM, 2011). In studies of sexually transmitted infections, sexual behavior is an obvious choice, but in research on health concerns for which societal stigma and discrimination play an important role, identity is more relevant (Hughes, 2011; Hughes, et al., 2015). We included questions about all three major dimensions of sexual orientation in both NSHLEW Wave 5 and CHLEW Wave 1. We also expanded the sexual orientation response options. For example, rather than asking women if they identified as heterosexual, lesbian, or bisexual, as many researchers continue to do, we included the intermediate responses of "mostly heterosexual" and "mostly lesbian." Subsequent studies have demonstrated that substance use outcomes vary based on whether these response options are included (Hughes et al., 2015, 2020; McCabe et al., 2012; Talley et al., 2016). The same sexual orientation questions have been asked at each wave.

\section{Drinking Measures}

As in the NSHLEW, we assessed participants' drinking levels using estimates of mean ounces of ethanol consumed per day. We combined information about drinking frequency and quantity, typical drink size, and ethanol content in the past 30 days, adjusting for frequency of HED. Light drinking was defined as $0.01-0.21 \mathrm{oz}$. ethanol/day $(0.01-4.90 \mathrm{~g})$; moderate drinking as $0.22-0.99 \mathrm{oz}$. ethanol/day $(5.0-22.9 \mathrm{~g})$; and heavier drinking as 1.00 or more oz. ethanol/day (23.0g or more). This drinking levels definition considered that a 12-ounce beer contains $4 \%$ ethanol, a 4-ounce glass of wine contains $15 \%$ ethanol, and a mixed drink contains 1 ounce of $45 \%$ ethanol liquor. HED in the NSHLEW and in the first three waves of CHLEW was assessed by asking about 12month frequency of consuming six or more drinks per day. (The definition of HED or "binge" drinking changed over the course of the study. Binge drinking is now defined for women as four or more drinks on one occasion [National Institute on Alcohol Abuse and Alcoholism, 2020]). We also asked about 12-month frequency of intoxication ("drinking noticeably affected your thinking, talking, and behavior"). Measures of drinking consequences assessed lifetime and previous12-month experiences of eight adverse drinking consequences (e.g., "driving a car while high from alcohol"). Examples of symptoms of potential alcohol dependence included blackouts, rapid drinking, and morning drinking. After Wave 3 we created a HD index of responses to four 12-month indicators: (a) HED, (b) intoxication, (c) adverse drinking consequences, and (d) symptoms of potential alcohol dependence (Riley et al., 2017). Other drinking measures (in all waves) include age of drinking onset, drinking contexts, drinking expectancies, and 30-day and 12-month quantity and frequency of partner's drinking. We asked participants in every CHLEW wave if they think they have/had a drinking problem, if they had sought help for a drinking problem, and if they are in recovery. We have retained most measures of drinking patterns, drinking problems, and major theoretical risk and protective factors across all waves.

\section{Other Measures}

In Wave 2 we added questions about current and early lesbian-specific drinking contexts, drinking norms, internalized homophobia, social support, and anti-gay workplace harassment. We omitted questions asked at baseline about early life experiences (e.g., childhood abuse, parental drinking problems) that did not need to be repeated. We also changed timeframes from lifetime or past five years to "since your previous interview" (with interview date specified) for many questions about adult experiences. In Wave 3, we added several new measures (e.g., lifetime changes in sexual identity, gender identity, legal relationship status and history, discrimination) and more comprehensive measures of posttraumatic stress disorder. Wave 4 added questions about perceived stress, coping, resilience, suicidality, family reactions to sexual identity disclosure, community connectedness, partners' race/ethnicity, 
perceived impact of same-sex marriage legalization, and expanded measures of intimate partner aggression (IPA). In this wave we also conducted an online survey to gather additional contextual information about the perceived impacts of legalized same-sex marriage and the 2016 U.S. Presidential election (Riggle et al., 2020). In addition, Hughes and colleagues conducted a national online survey (Drabble et al., 2019; Riggle et al., 2018b; Veldhuis et al., 2018) and a qualitative interview study with 20 SMW (Riggle et al., 2018a) to further disentangle the potential contradictory impacts of legalized same-sex marriage and the election of a conservative governing party.

In Wave 5 we broadened the range of questions to include factors found in recent literature to influence drinking patterns and problems (e.g., emotion regulation, positive and negative affect, and perceived stress). Wave 5 asks a full battery of questions about IPA, including whether the participant experienced or perpetrated various forms of IPA. We abbreviated measures of depression and CSA and included fewer drinking-related questions. Because more SMW now identify as queer, pansexual, polyamorous, or asexual (Suen et al., 2020), we added open-ended questions to better understand our sample's sexual identity label preferences. As in Wave 4 we included an online survey in Wave 5. In March 2020 we added questions to the online survey about the impact of COVID-19 on participants' lives and well-being, and conducted a qualitative study about impacts of the pandemic using a diverse subgroup of 18 CHLEW participants (Bochicchio et al., 2021).

\section{Recruitment, Retention and Description of the Study Sample}

Minority sexual orientation is relatively rare in the general population (Laumann et al., 1994). Even large general population surveys seldom include enough SMW to permit reliable statistical estimation. To obtain a large sample, and to maximize sample diversity, we used a range of recruitment methods and sources. At Wave 1 we targeted clusters of social networks such as formal community organizations and informal social groups, particularly those that included women of color, older women, and women of lower SES groups underrepresented in studies of lesbian health. Interested women were asked to call the project office to complete a brief eligibility screening. In addition to questions about age (18+), residence (the Greater Chicago [Illinois] Metropolitan Area) and language (English proficiency), we asked "Do you consider yourself to be lesbian, bisexual, heterosexual, transgender, or something else?" (At the time it was customary to include transgender identity in the same question as sexual identity.) Because resources in Wave 1 limited the number of interviews, we excluded women who identified as bisexual, heterosexual, or transgender. Participants recruited in Wave 1 were $18-83$ years old (37.5 years \pm 11.7$)$. Fewer than half identified as non-Hispanic white and most identified as exclusively lesbian. Although we excluded women who identified as bisexual when screened for eligibility, during the Wave 1 interview $11(2 \%)$ participants identified as such. The sample closely matched the racial/ethnic composition of adult females in Cook County, Illinois, where most participants lived (Chicago Fact Finder, 2002).
Wave 3 included a new supplemental sample recruited in 2010 to 2012. Based on an emerging literature showing that bisexual identity was at least as common as lesbian identity (Bostwick et al., 2010; Hughes et al., 2010) and that bisexual women were at greater risk than lesbian women of HD and other negative health behaviors (King et al., 2008; McCabe et al., 2009; Wilsnack et al., 2008), we added bisexual women in this wave. To increase their overall numbers, we added additional Black and Latinx women; we also added young women, ages 18-25. We made a concerted effort to recruit SMW with lower SES. This supplemental sample included 372 SMW of which $33 \%$ were ages 18-25, 37\% identified as bisexual and $76 \%$ as racial/ethnic minority (Black/African American, Hispanic/Latinx, mixed or multiracial). Demographic characteristics of the sample at each wave of the study are summarized in Table 1 .

This supplemental sample was recruited using a modified version of respondent-driven sampling (RDS; Heckathorn, 1997, 2002). According to Heckathorn (2002), if referral chains are sufficiently long, the composition of the sample will be independent of the seeds that began the process. We contacted SMW-serving organizations in Chicago and asked for help identifying SMW with large social networks. SMW who served as initial seeds were invited to recruit women with the desired sample characteristics. They were given three serially numbered coupons with a study description and a toll-free telephone number to distribute. New recruits were in turn interviewed, given three coupons, and invited to recruit other SMW. Women received $\$ 45$ for participating and $\$ 20$ for each eligible recruit (up to three). To protect confidentiality, interviewers did not know who made the referrals; participants were paid the recruitment incentive when coupons were turned in but did not necessarily know which of their contacts participated in the study. This recruitment method was less successful than anticipated (Martin et al., 2015) and we eventually invited all women enrolled in CHLEW to recruit other SMW to participate. (See the Lessons Learned subsection below for more information.) We continued this process with each newly recruited participant.

\section{Retention}

Data for Wave 1 were collected from April 2000 to October 2001. This 18-month timeframe helped ensure a large racially/ethnically- and age-diverse sample. In Wave 2, interviews were completed between July 2003 and May 2005; most were completed in 2003-2004, but data collection was extended to locate and interview harder-toreach participants. We retained $86 \%(n=384)$ of Wave 1 participants. For Wave 3 (May 2010-August 2012), we located and interviewed $79 \%$ of the Wave 1 sample $(n=354)$. As in Wave 2, this extended timeframe allowed us to maximize retention and to standardize the timeframe between interviews for each participant. We retained four participants who transitioned to male gender between Waves 2 and 3 but excluded them in analyses. In Wave 4 (April 2017-July 2019) we retained $73 \%(n=297)$ of the original sample and $62 \%(n=228)$ of the supplemental sample. Fifty participants were confirmed deceased and 93 were lost to follow-up; 16 women declined to participate, and we removed three participants who suffered from dementia and 
four who reported they had always identified as heterosexual. See Table 1 for sample sizes at Waves 1 to 4; Wave 5 data collection is currently in process.

To evaluate potential bias associated with attrition we examined 16 variables, including baseline sociodemographic variables, two major risk factors (CSA, depression), and drinking variables. Using stepwise logistic regression, we identified several predictors of retention (see Tables 3 and 4). Participants with higher education levels were more likely to be retained, as were those who reported a history of CSA at baseline. One or more drinking consequences in the last 12 months was associated with attrition at Wave 2; however, participants who reported any lifetime problem drinking consequences were more likely retained. At Wave 3 baseline education and CSA history were again associated with retention, as was younger participant age, whereas children $<18$ living at home and any past 12-month alcohol dependence symptoms were negatively associated. At Wave 4, education, CSA, younger age, and higher baseline household income were associated with retention; having children <18 living at home was associated with attrition in the original sample. For the supplemental sample, education was positively associated with retention, and any PTSD symptoms were negatively associated.

Table 1

CHLEW sample demographic characteristics

\begin{tabular}{|c|c|c|c|c|c|c|c|}
\hline CHLEW Study Wave & $\begin{array}{l}\text { Wave 1 } \\
\text { Original } \\
\text { Sample } \\
(n=447)\end{array}$ & $\begin{array}{l}\text { Wave } 2 \\
\text { Original } \\
\text { Sample } \\
(\mathbf{n}=384)\end{array}$ & $\begin{array}{l}\text { Wave 3 } \\
\text { Original } \\
\text { Sample } \\
(n=354)\end{array}$ & $\begin{array}{l}\text { Wave } 3 \\
\text { New Sample } \\
(n=372)\end{array}$ & $\begin{array}{l}\text { Wave } 4 \\
\text { Original } \\
\text { Sample } \\
(n=297)\end{array}$ & $\begin{array}{l}\text { Wave } 4 \\
\text { New Sample } \\
(n=228)\end{array}$ & $\begin{array}{l}\text { Wave } 4 \\
\text { Total } \\
\text { Sample } \\
(n=525)\end{array}$ \\
\hline Retention Rates & -- & $86 \%$ & $79 \%$ & -- & $73 \%$ & $62 \%$ & $68 \%$ \\
\hline \multicolumn{8}{|l|}{ Age } \\
\hline $18-24$ & 14.5 & 5.6 & 0.0 & 32.7 & 0.0 & 0.2 & 0.2 \\
\hline $25-30$ & 17.0 & 12.5 & 5.1 & 24.9 & 0.0 & 9.9 & 9.9 \\
\hline $31-40$ & 28.6 & 24.8 & 26.6 & 16.8 & 12.1 & 43.0 & 25.5 \\
\hline $41-50$ & 23.3 & 24.2 & 27.1 & 14.1 & 30.3 & 13.6 & 23.0 \\
\hline $51-60$ & 14.3 & 14.3 & 24.3 & 9.2 & 29.0 & 10.1 & 20.8 \\
\hline 61 or older & 2.2 & 4.5 & 16.9 & 2.4 & 28.6 & 10.1 & 20.6 \\
\hline \multicolumn{8}{|l|}{ Race/Ethnicity } \\
\hline AA/Black & 27.5 & 25.0 & 27.1 & 44.1 & 24.9 & 38.3 & 30.7 \\
\hline Hispanic/Latinx & 19.7 & 18.8 & 15.5 & 30.3 & 19.5 & 27.8 & 23.1 \\
\hline White & 47.7 & 51.0 & 51.4 & 24.1 & 50.5 & 30.8 & 42.0 \\
\hline Biracial/Multiracial & 5.1 & 5.2 & 5.9 & 1.6 & 5.1 & 3.1 & 4.2 \\
\hline \multicolumn{8}{|l|}{ Sexual Identity } \\
\hline Only lesbian & 70.5 & 68.8 & 62.2 & 48.1 & 61.6 & 37.7 & 51.2 \\
\hline Mostly lesbian & 26.6 & 21.6 & 18.8 & 14.3 & 18.2 & 16.7 & 17.5 \\
\hline Bisexual & 2.5 & 5.5 & 12.5 & 37.0 & 10.4 & 25.9 & 17.1 \\
\hline Mostly heterosexual & -- & 1.8 & 2.0 & 0.3 & 3.4 & 3.5 & 3.4 \\
\hline Only heterosexual & -- & 0.5 & 1.7 & 0.0 & 1.3 & 2.2 & 1.7 \\
\hline Asexual & -- & -- & 0.0 & 0.0 & 0.7 & 0.0 & 0.4 \\
\hline Other & 0.4 & 1.8 & 1.7 & 0.3 & 4.4 & 14.0 & 8.6 \\
\hline \multicolumn{8}{|l|}{ Educational Level } \\
\hline Less than HS & 2.9 & 1.3 & 0.6 & 14.6 & 0.3 & 7.0 & 3.2 \\
\hline High school & 10.7 & 7.3 & 6.8 & 17.0 & 5.1 & 12.8 & 8.4 \\
\hline Some college & 30.2 & 26.0 & 21.5 & 40.3 & 19.5 & 32.6 & 25.1 \\
\hline Bachelors & 26.4 & 29.7 & 27.2 & 16.2 & 26.3 & 23.3 & 25.0 \\
\hline Graduate degree & 29.8 & 35.7 & 43.9 & 11.9 & 48.8 & 24.2 & 38.2 \\
\hline \multicolumn{8}{|l|}{ Household Income } \\
\hline Less than $\$ 15,000$ & 19.3 & 10.5 & 10.3 & 44.3 & 6.9 & 19.0 & 14.3 \\
\hline$\$ 15-\$ 29,999$ & 16.1 & 14.4 & 11.2 & 14.5 & 7.9 & 23.1 & 14.1 \\
\hline$\$ 30-\$ 49,999$ & 25.9 & 25.2 & 17.0 & 20.6 & 15.1 & 17.2 & 15.6 \\
\hline$\$ 50-\$ 99,999$ & 26.3 & 34.4 & 31.9 & 16.6 & 32.3 & 26.2 & 28.9 \\
\hline$\$ 100,000$ or more & 12.5 & 15.5 & 20.6 & 4.1 & 37.8 & 14.5 & 27.1 \\
\hline \multicolumn{8}{|l|}{ Relationship Status ${ }^{\text {a }}$} \\
\hline Not living together & 22.0 & 16.8 & 15.1 & 29.3 & 11.5 & 15.4 & 13.1 \\
\hline $\begin{array}{l}\text { Living together } \\
\text { /married }\end{array}$ & 47.0 & 52.4 & 49.1 & 29.6 & 54.7 & 39.5 & 48.0 \\
\hline Separated & 0.7 & 3.1 & 7.1 & 2.2 & 2.4 & 5.7 & 3.1 \\
\hline Divorced & 4.5 & -- & -- & -- & -- & -- & -- \\
\hline $\begin{array}{l}\text { Not in committed } \\
\text { relationship }\end{array}$ & 5.7 & 27.7 & 27.6 & 38.3 & 30.4 & 38.2 & 33.7 \\
\hline Never married & 19.5 & -- & -- & -- & -- & -- & -- \\
\hline Widowed & 0.5 & -- & 1.1 & 0.5 & 1.0 & 1.3 & 1.1 \\
\hline Children < 18 yrs. living & 19.1 & 19.0 & 19.6 & 20.3 & 16.8 & 21.3 & 18.9 \\
\hline
\end{tabular}

Notes: Four original sample participants identified as transgender in Wave 3; all identified as sexual minority.

${ }^{a}$ Relationship status categories are not mutually exclusive. 


\section{Data Collection}

For each study wave, we conducted 2-day training sessions with a diverse group of five or six female interviewers shortly before data collection. Wave 1 training was conducted by NORC staff, the project manager, and Drs. Hughes and Wilsnack. All subsequent trainings were conducted by members of the research team. Trainings included self-study materials covering interview content, exercises to increase sensitivity to SMW and other stigmatized populations, and completion of several mock interviews. Although we moved from paper-pencil interviewing in Wave 1 to computer-assisted interviewing in Waves 2 to 5 , and from in-person interviews in Waves 1 to 3 to telephone interviews in Waves 4 to 5 , the same content was covered in trainings for all study waves.

In Wave 1, participants responded to some questions (e.g., sexual behavior) in a self-administered handout that they completed privately, inserted into an envelope, sealed, and returned to the interviewer. In Waves 2 to 3 participants interviewed in person were handed the laptop computer for the self-administered section. For phone interviews this section was mailed to participants who completed and returned it by mail. Waves 4 and 5 did not include selfadministered handouts. Instead (to reduce respondent burden from lengthy phone interviews) participants completed a separate, online survey that included the more sensitive questions as well as a number of other questions. See Table 2 for dates and modes of data collection.

\section{Informed Consent}

At each study wave, following a review of the study's purpose, participants were instructed to read, ask any questions, and sign a consent form approved by the University of Illinois at Chicago (UIC) Institutional Review Board. Because the CHLEW PI moved from UIC to Columbia University, Waves 4 and 5 were also reviewed and approved by that institution's Institutional Review Board.

\section{Changes in Modes of Data Collection}

In Wave 1 all participants were interviewed face-to-face in a private setting. In Wave 2 we followed the same procedures as in Wave 1 except we switched from paper and pencil data collection to computer-assisted personal interviewing (CAPI). Advantages of CAPI include: (a) preventing interviewers from incorrectly skipping; (b) preventing inadmissible responses; and (c) reducing data entry errors and (d) data processing time (Bradburn et al., 1991).

Between Waves 1 and 3, 102 participants moved from the Chicago area, requiring many Wave 3 interviews to be conducted by telephone. Other additional interviews were conducted by phone because of scheduling difficulties or participant preference. To assess potential mode effects, we compared self-reports of alcohol and drug use among participants interviewed in person with those interviewed by telephone. Although women interviewed by telephone were less likely to report use of cocaine, we found no differences in any of the HD outcomes. These findings were consistent with assessments of the 1990 and 2000 National Alcohol Surveys (Greenfield, 2000; Midanik \& Greenfield, 2008). By Wave 4, 180 participants had moved outside the Chicago area. Given participant mobility and the costs of in-person interviewing, we transitioned fully to computer-assisted telephone interviewing (CATI) in Waves 4 and 5. Our finding of limited mode effects in Wave 3 indicated that this would not significantly influence self-report on key measures.

Across all waves interviews have lasted 90 minutes on average. Interview length has generally not been a problem in our surveys (rather, many participants have expressed appreciation for the opportunity to talk about their life experiences). Although potentially sensitive questions are asked, few participants have become upset and nearly all have answered all questions.

Table 2

Dates, modes of data collection, and number of questions

\begin{tabular}{|c|c|c|c|c|c|}
\hline & Wave 1 & Wave 2 & Wave 3 & Wave 4 & $\begin{array}{c}\text { Wave } 4 \\
\text { online } \\
\text { supplemental } \\
\text { survey }\end{array}$ \\
\hline Field dates & $\begin{array}{l}\text { April } 2000 \text { to } \\
\text { October } 2001\end{array}$ & $\begin{array}{l}\text { July } 2003 \text { to May } \\
2005\end{array}$ & $\begin{array}{l}\text { May } 2010 \text { to } \\
\text { August } 2012\end{array}$ & $\begin{array}{l}\text { April } 2017 \text { to } \\
\text { July } 2019\end{array}$ & $\begin{array}{l}\text { April } 2017 \text { to } \\
\text { July } 2019\end{array}$ \\
\hline $\begin{array}{l}\text { Mode(s) of data } \\
\text { collection }\end{array}$ & PAPI & CAPI & CAPI & CATI & $\begin{array}{c}\text { Online self- } \\
\text { administered } \\
\text { Qualtrics survey }\end{array}$ \\
\hline $\begin{array}{l}\text { Number of } \\
\text { Questions }\end{array}$ & $\begin{array}{l}355 \\
\text { (poss. } 1006 \text { with } \\
\text { follow-up) }\end{array}$ & $\begin{array}{c}417 \\
\text { (poss. 1300) }\end{array}$ & $\begin{array}{l}\text { Original sample } 426 \\
\text { (poss. 1750) } \\
\text { RDS sample } 447 \\
\text { (poss. 1914) }\end{array}$ & 467 (poss. 785) & $\begin{array}{l}12 \text { open-ended } \\
59 \text { close-ended }\end{array}$ \\
\hline
\end{tabular}

Note: PAPI - paper and pencil in-person interview; CAPI - computer assisted in person interview; CATI - computer-assisted telephone interview. Number of follow-up questions substantially fewer for participants who reported not having consumed alcohol in the previous 12 months. Single participants asked 1-25 fewer questions, depending on survey wave. 


\section{Results}

The 20-year CHLEW has produced a wealth of findings (see Appendix 1 for a summary of 56 publications) and is a valuable resource for examining mechanisms underlying SMW's heightened risk of HD. The study's large subsamples of women over 50 years old, and of Black, Hispanic/Latinx, and bisexual women, provide rare opportunities to examine the impact of age, race/ethnicity, and sexual identity - and their intersections - on relationships between risk and protective factors and HD. Below we provide brief summaries of key findings from a few of our published papers.

\section{Comparisons of Drinking across Sexual Identity Groups}

In a combined sample of women ages 21-70 in CHLEW Wave 1 (2000-2001) and NSHLEW Wave 5 (2001) we compared rates of HD (HED, intoxication, drinking-related problems, alcohol-dependence symptoms) across exclusively heterosexual, mostly heterosexual, bisexual, mostly lesbian, and exclusively lesbian subgroups. Exclusively heterosexual women had lower rates than all other groups on all measures of HD. Exclusively heterosexual women also reported less childhood sexual abuse, early alcohol use, and depression. Bisexual women reported more HD indicators and depression than did exclusively or mostly lesbian women (Wilsnack et al., 2008).

\section{Victimization}

To understand how differences in sexual identity and victimization experiences influence risk of $\mathrm{HD}$ and depression we pooled data from CHLEW Wave 1 and NSHLEW Wave 5 to compare rates of victimization, HD, and depression across five sexual identity subgroups. Rates varied substantially by sexual identity, with bisexual and mostly heterosexual women showing significantly higher risk than exclusively heterosexual women on one or both of the study outcomes. The number of victimization experiences explained some, but not all, of the risk of HD and depression among SMW, suggesting that other factors, such as stigma and discrimination, likely play a role in HD and mental health disparities among SMW (Hughes et al., 2014).

\section{Models of HD}

Using data from the first two waves of CHLEW we tested models that included HD, depression, and anxiety along with early risk factors and unique social stressors experienced by SMW. Consistent with a self-medication process, anxiety was prospectively associated with HD. And, consistent with an impaired functioning process, HD was prospectively associated with depression. These findings support a life course perspective that interprets the mental health of adult SMW as influenced by adverse childhood experiences, age at drinking onset, first heterosexual intercourse, and first sexual identity disclosure, as well as by processes associated with self-medication and impaired functioning during adulthood (Johnson et al., 2013).

\section{Changing Sexual Identities}

Although a good deal has been written about fluidity of women's sexual orientation (Diamond, 2016; Mereish et al., 2017; Ott et al., 2011), the dearth of prospective studies limits relevant empirical evidence. In the CHLEW $26 \%$ of the sample reported a sexual identity change between Wave 1 and Wave 2, and 25\% reported a change between Waves 2 and 3 . Women who reported a change also reported more depressive symptoms subsequent to identity change. This effect was moderated by the length of time participants had identified in a particular way and whether they had initiated a romantic relationship with a male partner (Everett et al., 2016b).

\section{Drinking, Aging and Health}

There is ample evidence that self-perceptions of mental and physical health are important predictors of health outcomes and well-being, particularly among older adults. We examined associations among age, drinking, and self-rated mental and physical health in CHLEW Wave 3 (Veldhuis et al., 2017). Heavy drinking among older adult SMW (55+) was less prevalent than among those ages 18-39, but similar to rates among SMW ages 40-54. In addition, older SMW reported significantly better mental health than SMW in the younger age groups, but we found no significant associations between age and self-rated physical health. Across all age groups, moderate drinkers reported better self-rated physical health than alcohol abstainers. These results suggest that drinking does not decline as sharply with age among SMW as among women in general population surveys.

\section{Risk of Mortality}

Forty-nine of CHLEW participants recruited in 2000-01 or 2010-12 (6.3\% of the sample) were confirmed dead by 2019 . The mean age at death was 56.5 years. Adjusting for key sociodemographic, SM stress, and health variables (e.g., race/ethnicity, education, HD, smoking, depression, internalized homophobia), we found that level of sexual identity disclosure was the most robust predictor of mortality. SMW who had disclosed their sexual identity to $100 \%$ of their immediate family members had a $70 \%$ lower risk of mortality than SMW who disclosed to less than onethird of their immediate family. These results suggest that facilitating family acceptance of SMW may have important implications for health and life expectancy among SMW (Everett et al., 2021).

\section{Drinking Trajectories}

We recently examined adult role acquisitions and exposure to SM stress as predictors of latent trajectories of HD in Waves 1 to 3. SMW who transitioned to parenthood were less likely to show persistent elevated risk of HED and less likely to report HED beyond young adulthood. Consistent with minority stress theory, SMW who reported higher levels of perceived SM stigma, and those who reported higher levels of masculinity showed persistently elevated risk of alcohol dependence (Talley et al., in review). 


\section{Impact of Supportive Policies}

In Wave 3 we conducted a quasi-experiment to test the impact of the Illinois Civil Unions Bill (which provided some, but not all, of the rights afforded by marriage). We compared minority stressors, mental health, and HD among SMW interviewed before the Bill passed in late 2010; after passing, but before signed into law; and after signed into law in June 2012. Civil union legislation was associated with lower levels of stigma consciousness, perceived discrimination, depressive symptoms, and HD among all SMW in CHLEW. For several other outcomes, the benefits of this supportive policy were largely concentrated among racial/ethnic minorities and those with lower education levels. These results suggest that policies supportive of SM civil rights may be most beneficial for women with multiple marginalized statuses (Everett et al., 2016a).

\section{Generalizability of Findings}

Using data from the U.S. National Alcohol Survey (NAS), a probability sample, and CHLEW Wave 3, we compared findings related to $\mathrm{HD}$, drug use, and depression. Regardless of sample type, we found significantly greater odds among SMW than heterosexual women in 21 of 23 comparisons (12 with the full sample and 11 with drinkers only). Odds of HD were elevated in the NAS SMW sample relative to heterosexual women, but differences did not reach significance. Findings suggest that high levels of HD, drug use, and depression found in non-probability samples of sexual minorities are not artifacts of the sampling method (Drabble et al., 2018).

See Appendix 1 for key findings from all CHLEW publications to date

Table 3

Results of stepwise logistic regression to predict original sample panel retention (1=yes; $0=n o$ ) at Waves 2 to 4 using Wave 1 baseline variables.

\begin{tabular}{|c|c|c|c|}
\hline & Wave 2 & Wave 3 & Wave 4 \\
\hline \multicolumn{4}{|l|}{ Socio-demographics } \\
\hline Respondent education & $\begin{array}{c}2.03 \\
(1.51-2.73)^{* * *}\end{array}$ & $\begin{array}{c}1.60 \\
(1.27-2.03)^{* * *}\end{array}$ & $\begin{array}{c}1.36 \\
(1.08-1.70)^{* *}\end{array}$ \\
\hline Respondent age & -- & $\begin{array}{c}0.97 \\
(0.95-0.99)^{* *}\end{array}$ & $\begin{array}{c}0.96 \\
(0.94-0.98)^{* * *}\end{array}$ \\
\hline Children $<18$ at home (Wave 1) & -- & $0.38(0.21-0.68)^{* * *}$ & $0.57(0.34-0.96)^{*}$ \\
\hline Household income (Wave 1) & -- & -- & $\begin{array}{c}1.06 \\
(1.02-1.11)^{* *}\end{array}$ \\
\hline \multicolumn{4}{|l|}{ Alcohol use } \\
\hline $\begin{array}{l}\text { Any past } 12 \text {-month alcohol dependence } \\
\text { symptoms (Wave 1) }\end{array}$ & -- & $\begin{array}{c}0.40 \\
(0.22-0.72)^{* *}\end{array}$ & -- \\
\hline $\begin{array}{l}\text { Any past } 12 \text {-month problem consequences } \\
\text { (Wave 1) }\end{array}$ & $\begin{array}{c}0.20 \\
(0.09-0.45)^{* * *}\end{array}$ & -- & -- \\
\hline Ever any problem consequences (Wave 1 ) & $\begin{array}{c}2.39 \\
(1.07-5.34)^{*}\end{array}$ & -- & -- \\
\hline \multicolumn{4}{|l|}{ Other risk factors } \\
\hline $\begin{array}{l}\text { Felt sexually abused when growing up } \\
\text { (Wave 1) }\end{array}$ & $\begin{array}{c}2.86 \\
(1.34-6.08)^{* *}\end{array}$ & $\begin{array}{c}2.66 \\
(1.44-4.94)^{* *}\end{array}$ & $\begin{array}{c}1.66 \\
(1.03-2.68)^{*}\end{array}$ \\
\hline Nagelkerke R-square & 0.20 & 0.15 & 0.12 \\
\hline (n) & $(423)$ & (423) & (423) \\
\hline
\end{tabular}

\section{Lessons Learned}

\section{Recruitment and Retention}

In conducting a longitudinal study over more than 20 years with a marginalized population group, we have learned a great deal. First, recruitment and retention are challenging, especially when the sample is as diverse as CHLEW's. Community involvement and relationship building are key. As a member of the SMW community, Dr. Hughes deeply engaged with various community organizations that serve SMW in Chicago. This "insider" position assists in gaining the trust of gatekeepers and potential study participants. We strive to include interviewers who are SMW of various ages and racial/ethnic backgrounds. Dr. Hughes and the first project manager, a self-identified Latinx lesbian, attended multiple community events to present information about SMW's health, describe CHLEW, and distribute materials encouraging eligible women to participate. Images of our Black and Latinx interviewers on flyers and brochures served to increase SMW of color's interest. Although a successful recruitment method in some studies, especially men who have sex with men (Johnston et al., 2016), our use 
of RDS to recruit SMW in Wave 3 was less successful (Martin et al., 2015). More recent reports describe greater success using RDS to recruit SMW (Hequembourg \& Panagakis, 2019; Michaels et al., 2019).

Table 4

Results of stepwise logistic regression to predict supplemental sample panel retention $(1=y e s ; 0=n o)$ at Wave 4 using Wave 3 variables

Level of education (Wave 3) 1.377 $(\mathrm{CI}=1.107-1.713)^{* *}$

Any past 12-month PTSD symptoms (Wave 3 ) 0.607 $(\mathrm{CI}=0.370-0.995)^{*}$

Nagelkerke R-square 0.069

$* p<.05 ; * * p<.01 ; * * * p<.001$

An important recruitment (and retention) strategy has been graduated monetary incentives for study participation $(\$ 35$ in Wave 1, \$45 in Wave 2, \$50 in Wave 3, \$60 in Waves 4 and 5). Incentives are a tangible recognition of the value of participants' time and contribution (Holbrook et al., 2019). In Waves 1 to 3 we provided cash incentives. Following the move to telephone interviews we began mailing money orders to participants. Participants prefer cash or money orders over gift or bank cards which are not as easy to use.

Over time we have adapted other strategies to support retention. For example, we initially asked participants to provide contact information for two people who would always know their whereabouts, but in Wave 3 we increased the number to four people. We also expanded our use of locating strategies to include the Social Security Death Index and social media platforms such as Instagram, Twitter, and Facebook.

Because we learned that intensive follow-up and contact improves participation, we communicate with participants multiple times each year (e.g., we send letters with return postcards requesting address changes or confirmation at 6 month intervals, and birthday and holiday cards every year; we also periodically send newsletters with basic study findings) and small gifts (e.g., magnets with the CHLEW logo) as tokens of appreciation. We provide all participants our toll-free telephone number and email address and encourage them to contact us with any suggestions, questions, or concerns. We send letters informing participants when new funding is obtained and clearly communicate our appreciation of their role in CHLEW's continuing success. We strive to communicate study benefits (e.g., improving healthcare providers' understanding of SMW's unique health concerns). We emphasize confidentiality and convenient scheduling and provide participants a list of local substance use treatment and mental health resources should they want to seek help.

Despite these multiple retention strategies, attrition has increased over the years, partly because we deliberately targeted hard-to-reach SMW, especially when recruiting the Wave 3 supplemental sample. A substantial number of new Wave 3 participants were low-SES and transient; some lived in group homes. However, a growing number of original
(Wave 1) participants have also dropped out of the study. Over the past 20 years SM people have become much more visible and accepted (Flores, 2019), perhaps making studies such as the CHLEW less salient. Another factor is the loss of participants who have died (54 deaths as of May 2021).

\section{Funding}

Funding was not always timely and this affected our capacity to answer some key policy questions. For instance, the Wave 4 and 5 grant application was submitted in November 2014, but not funded until September 2016. We had proposed two waves of data collection in this phase because we hoped to gather data soon after same-sex marriage was legalized in Illinois (June 2014) and again two years later-to determine whether the impact of this presumably positive policy change would be sustained over time. We anticipated that this new law would have beneficial effects for all SMW, and that married SMW would demonstrate many of the health benefits of marriage observed among women in the general population. We were unable to begin data collection until 2017, three years after Illinois legalized same-sex marriage and two years after it was legal throughout the U.S. (June 2015), which will make it difficult to determine whether observed drinking changes were the result of the new marriage law or other factors, such as the election of a conservative federal government in November 2016. Because the study was not funded on first submission, we applied for and received bridge funding that allowed us to retain core research staff and continue efforts to track and retain study participants.

\section{Changing Definitions of Key Variables}

As in all long-term prospective studies, changing definitions of key variables (e.g., alcohol use disorder, HED) has been a challenge. Carrying forward "old" measures to permit longitudinal analyses and adding new, improved versions in each wave increase the length of the interview, adding to respondent burden. Over time we have learned that managing participant burden is more important than including all variables that seem important to assess.

Because the CHLEW was designed to focus on SMW, questions in Waves 1 to 3 did not ask about gender identity. Given the growing visibility of individuals who identify as transgender or gender nonbinary we expanded our gender identity questions in Wave 4. More than 20 participants identified as transgender, nonbinary, genderqueer, or "other." As mentioned above, we have observed substantial changes in the way participants describe their sexual identity. To address these changes, we ask several openended questions to better understand participants' choice of identity labels.

\section{Possible Misrepresentation of Sexual Identity}

All researchers who rely on self-report data must recognize that some study participants may misrepresent themselves so that they meet eligibility criteria and can receive participant incentives; this is an even greater challenge when participants can easily "hide" their marginalized identities. In CHLEW this was most apparent when we used RDS to recruit the Wave 3 supplemental sample. Once interviewed, 
participants could receive $\$ 20$ per referral for up to three successful recruits. We noticed a potential problem when a few participants appeared unfamiliar with the acronym LGBT or reported no history of same-sex attraction or behavior. The problem became clearer in Wave 4 when four participants reported they had always identified as heterosexual. This seemed to be less of an issue in our original sample, but we identified two Wave 2 participants who appeared to have mischaracterized their sexual identity in Wave 1. We learned to train our interviewers to pay particular attention to unusual or inconsistent responses, and the research staff learned to be cautious about tapping into social networks of women who share similar characteristics not related to their sexual identity when recruiting study participants. For example, in Wave 3, after receiving several referrals of women with the same address, we learned that one study participant from a homeless residential service had spread the word about the study and its financial incentive to other residents. Hence, we learned to pay close attention to duplicate addresses of referred women.

\section{Falsification of Data}

About six months into data collection in Wave 1 we discovered that one of the study interviewers had falsified several interviews. We reviewed all interviews conducted by this interviewer to ensure that her other interviews were valid, and we telephoned most of the participants she had interviewed to do further validation checks. Based on this experience we began conducting validation checks on $10 \%$ of all completed interviews (i.e., the project manager or field coordinator calls study participants and asks a few "quality assurance" questions). The project staff also meets regularly with interviewers to discuss work quality, problems encountered in conducting interviews, and strategies for dealing with difficult situations.

Despite the challenges, longitudinal research provides invaluable benefits, such as understanding changes in health behaviors and mechanisms underlying such changes. One of the gratifying aspects of the longitudinal CHLEW study is that many participants feel invested in the research. Examples of participant comments include "I haven't read any study results, but I know that there isn't a lot of information out there about our community," "Happy to be in the study. It is rare. I never imagined it would go on so long." "I really like the cards that you send to keep me involved through the years." Another participant stated, "I really like being a part of something that will hopefully give results and information to benefit others."

\section{Conclusion}

Findings from the CHLEW study have made substantial contributions to understanding variations in SMW's risk for hazardous/harmful drinking based on sexual identity, age, race/ethnicity, relationship status and commitment, and sex/gender of partner. We have also added to knowledge about the associations of HD with violence/victimization, mental health, unintended pregnancy, smoking, and cardiovascular health. Our findings highlight the negative impact of minority stress on SMW's health and the importance of supportive policies and societal acceptance in mitigating such risks. By describing the process used in conducting this long-term study, its major findings, and the lessons learned, we hope to encourage and support other researchers in conducting longitudinal research focused on SMW's health. Such research is critically important in understanding and ultimately eliminating sexual orientationrelated health disparities.

\section{Acknowledgements}

The authors would like to acknowledge the women who have participated in the Chicago Health and Life Experiences of Women study (2000-present) or the National Study of Health and Life Experiences of Women (1980-2001). We would also like to acknowledge the many individuals who have served as co-investigators, consultants, or in other capacities for these studies. Finally, a special thanks to Dr. Lauren Porsch for formatting the manuscript.

\section{References}

Bloomfield, K. (1993). A comparison of alcohol consumption between lesbians and heterosexual women in an urban population. Drug and Alcohol Dependence, 33(3), 257-269. $\quad$ https://doi.org/10.1016/03768716(93)90112-4

Bochicchio, L., Drabble, L.A., Riggle, E.D.B., Munroe, C., Wootton, A.R. \& Hughes, T.L. (2021). Understanding alcohol and marijuana use among sexual minority women during COVID-19: A descriptive phenomenological study. Journal of Homosexuality, 68(4), 631-646. https:/doi.org/10.1080/00918369.2020.1868187

Bostwick, W. B., Boyd, C. J., Hughes, T. L., \& McCabe, S. E. (2010). Dimensions of sexual orientation and the prevalence of mood and anxiety disorders in the United States. American Journal of Public Health, 100(3), 468475. https://doi.org/10.2105/AJPH.2008.152942

Bradburn, N. F., MR; Baker, RP; \& Pergamit MR. (1991). A comparison of computer-assisted personal interviews (CAPI) with paper-and-pencil interviews (PAPI) in the National Longitudinal Survey of Youth. NLS Discussion Paper, (No. 92-2). Washington, D.C.

Brady, K. T., Back, S. E., \& Greenfield, S. F. (Eds.) (2009). Women and Addiction: A Comprehensive Handbook. Guilford Press.

Chicago Fact Finder. (2002). Census Data 1990 and 2000. University of Notre Dame: Institute for Latino Studies.

Cochran, S. D., \& Mays, V. M. (2000). Lifetime prevalence of suicide symptoms and affective disorders among men reporting same-sex sexual partners: Results from Nhanes III. American Journal of Public Health, 90(4), 573-578.

Diamond, L.M. (2016). Female sexual orientation. In A. Goldberg (Ed.), The Sage encyclopedia of LGBTQ lives in context (pp. 551-556). Sage.

Drabble, L.A., Trocki, K.F., Korcha, R.A., Klinger, J.L., Veldhuis, C.B., \& Hughes, T.L. (2018). Comparing substance use and mental health outcomes among sexual minority and heterosexual women in probability and non-probability samples. Drug and Alcohol 
Dependence,

185 , https://doi.org/10.1016/j.drugalcdep.2017.12.036

Drabble, L. A., Veldhuis, C. B., Wootton, A., Riggle, E. D. B., \& Hughes, T. L. (2019). Mapping the landscape of support and safety among sexual minority women and gender non-conforming individuals: Perceptions after the 2016 US Presidential Election. Sexuality Research and Social Policy, 16(4), 488-500. https://doi.org/10.1007/s13178-018-0349-6

Everett, B. G., Hatzenbuehler, M. L., \& Hughes, T. L. (2016a). The impact of civil union legislation on minority stress, depression, and hazardous drinking in a diverse sample of sexual-minority women: A quasinatural experiment. Social Science and Medicine, 169, $180-190$ https://doi.org/10.1016/j.socscimed.2016.09.036

Everett, B. G., Talley, A. E., Hughes, T. L., Wilsnack, S. C., \& Johnson, T. P. (2016b). Sexual identity mobility and depressive symptoms: A longitudinal analysis of moderating factors among sexual minority women. Archives of Sexual Behavior, 45(7), 1731-1744. https://doi.org/10.1007/s10508-016-0755-x

Everett, B.G., Wall, M., Shea, E., \& Hughes, T.L. (2021). Mortality risk among a sample of sexual minority women: The role of sexual identity disclosure. Social Science \& Medicine, 272, 113731. https://doi.org/10.1016/j.socscimed.2021.113731

Finnegan, D., \& McNally, E. (1990). Lesbian Women. In R. Engs (Ed.), Women: Alcohol and Other Drugs (pp. 149156). Resource Publications.

Flores, A. R. (2019). Social acceptance of LGBT people in 174 countries: 1981 to 2017. https://escholarship.org/uc/item/5qs218xd

Geary, R. S., Tanton, C., Erens, B., Clifton, S., Prah, P., Wellings, K., Mitchell, K. R., Datta, J., Gravningen, K., Fuller, E., Johnson, A. M., Sonnenberg, P., \& Mercer, C. H. (2018). Sexual identity, attraction and behaviour in Britain: The Implications of using different dimensions of sexual orientation to estimate the size of sexual minority populations and inform public health interventions. PloS One, 13(1), e0189607. https://doi.org/10.1371/journal.pone.0189607

Gilman, S. E., Cochran, S. D., Mays, V. M., Hughes, M., Ostrow, D., \& Kessler, R. C. (2001). Risk of psychiatric disorders among individuals reporting same-sex sexual partners in the National Comorbidity Survey. American Journal of Public Health, 91(6), 933-939. https://doi.org/10.2105/ajph.91.6.933

Greenfield, T. K. (2000). Ways of measuring drinking patterns and the difference they make: Experience with Graduated Frequencies. Journal of Substance Abuse, 12(1-2), 33-49. https://doi.org/10.1016/s08993289(00)00039-0

Heckathorn, D. D. (1997). Respondent-driven sampling: A new approach to the study of hidden populations. Social Problems, 44(2), 174-199. https://doi.org/10.2307/3096941

Heckathorn, D. D. (2002). Respondent-driven sampling II: Deriving valid population estimates from chain-referral samples of hidden populations. Social Problems, 49(1), 11-34. https://doi.org/10.1525/sp.2002.49.1.11
Heffernan, K. (1998). The nature and predictors of substance use among lesbians. Addictive Behaviors, 23(4), 517528. https://doi.org/10.1016/S0306-4603(98)00003-3

Hequembourg, A. L., \& Panagakis, C. (2019). Maximizing respondent-driven sampling field procedures in the recruitment of sexual minorities for health research. SAGE Open Medicine, 7, 2050312119829983. https://doi.org/10.1177/2050312119829983

Holbrook, A. L., Sterrett, D., Crosby, A. W., Stavrakantonak , M., Wang, X., Zhao, T., \& \& Johnson, T. P. (2019). Survey experiments and changes in question wording in repeated cross-sectional surveys. In M. W. T. P.J. Lavrakas, C. Kennedy, C., A.L. Holbrook, E. L. de Leeuw, E.L., \& West, B.T. (Ed.), Experimental methods in survey research (pp. 343-367). Wiley.

Hughes, T. (2011). Alcohol use and alcohol-related problems among sexual minority women. Alcoholism Treatment Quarterly, 29(4), 403-435. https://doi.org/10.1080/07347324.2011.608336

Hughes, T., McCabe, S. E., Wilsnack, S. C., West, B. T., \& Boyd, C. J. (2010a). Victimization and substance use disorders in a national sample of heterosexual and sexual minority women and men. Addiction, 105(12), 21302140. https://doi.org/https://doi.org/10.1111/j.13600443.2010.03088.x

Hughes, T., Szalacha, L. A., \& McNair, R. (2010b). Substance abuse and mental health disparities: Comparisons across sexual identity groups in a national sample of young Australian women. Social Science and Medicine, 71(4), 824-831. https://doi.org/10.1016/j.socscimed.2010.05.009

Hughes, T., Veldhuis, C., Drabble, L., \& Wilsnack, S. (2020). Research on alcohol and other drug (AOD) use among sexual minority women: A global scoping review. PloS One, 15(3), e0229869. https://doi.org/10.1371/journal.pone.0229869

Hughes, T., Wilsnack, S., \& Johnson, T. (2005). Investigating lesbians' mental health and alcohol use: What Is an appropriate comparison group? In A. Omoto \& H. Kurtzman (Eds.), Sexual orientation and mental health: Examining identity and development in lesbian, gay, and bisexual people (pp. 167-184). American Psychological Association.

Hughes, T. L., \& Eliason, M. (2002). Substance use and abuse in lesbian, gay, bisexual and transgender populations. Journal of Primary Prevention, 22(3), 263298. https://doi.org/10.1023/a:1013669705086

Hughes, T. L., Johnson, T., \& Wilsnack, S. C. (2001). Sexual assault and alcohol abuse: A comparison of lesbians and heterosexual women. Journal of Substance Abuse, 13(4), $515-532$. https://doi.org/10.1016/s08993289(01)00095-5

Hughes, T. L., Johnson, T. P., Steffen, A. D., Wilsnack, S. C., \& Everett, B. (2014). Lifetime victimization, hazardous drinking, and depression among heterosexual and sexual minority women. LGBT Health, 1(3), 192203. https://doi.org/10.1089/lgbt.2014.0014

Hughes, T. L., Johnson, T. P., Wilsnack, S. C., \& Szalacha, L. A. (2007a). Childhood risk factors for alcohol abuse and psychological distress among adult lesbians. Child Abuse \& Neglect, 31(7), 769-789. https://doi.org/10.1016/j.chiabu.2006.12.014 
Hughes, T. L., \& Wilsnack, S. C. (1994). Research on lesbians and alcohol: Gaps and implications. Alcohol Health and Research World, 18(3), 202-205.

Hughes, T. L., \& Wilsnack, S. C. (1997b). Use of alcohol among lesbians: Research and clinical implications. American Journal of Orthopsychiatry, 67(1), 20-36. https://doi.org/10.1037/h0080208

Hughes, T. L., Wilsnack, S. C., \& Kantor, L. W. (2016). The influence of gender and sexual orientation on alcohol use and alcohol-related problems: Toward a global perspective. Alcohol Research: Current Reviews, 38(1), 121-132.

Hughes, T. L., Wilsnack, S. C., \& Kristjanson, A. F. (2015). Substance use and related problems among U.S. women who identify as mostly heterosexual. BMC Public Health, 15, 803. https://doi.org/10.1186/s12889-0152143-1

Institute of Medicine (IOM) (US) Committee on Lesbian Health Research Priorities, \& Solarz, A. L. (Ed.). (1999). Lesbian Health: Current Assessment and Directions for the Future. National Academies Press (US).

Institute of Medicine (IOM). (2011). The health of lesbian, gay, bisexual, and transgender people: Building a foundation for better understanding [eBook] (pp. 1366). https://doi.org/10.17226/13128

Johnson, T. P., Hughes, T. L., Cho, Y. I., Wilsnack, S. C., Aranda, F., \& Szalacha, L. A. (2013). Hazardous drinking, depression, and anxiety among sexualminority women: Self-medication or impaired functioning? Journal of Studies on Alcohol and Drugs, 74(4), $565-575$ https://doi.org/10.15288/jsad.2013.74.565

Johnston, L. G., Hakim, A. J., Dittrich, S., Burnett, J., Kim, E., \& White, R. G. (2016). A Systematic Review of Published Respondent-Driven Sampling Surveys Collecting Behavioral and Biologic Data. AIDS and Behavior, 20(8), $1754-1776$ https://doi.org/10.1007/s10461-016-1346-5

King, M., Semlyen, J., Tai, S. S., Killaspy, H., Osborn, D., Popelyuk, D., \& Nazareth, I. (2008). A systematic review of mental disorder, suicide, and deliberate self harm in lesbian, gay and bisexual people. $B M C$ Psychiatry, 8(1), 70. https://doi.org/10.1186/1471-244x$\underline{8-70}$

Laumann, E., Gagnon, J., Michael, R., \& Michaels, S. (1994). The social organization of sexuality: Sexual practices in the United States. University of Chicago Press.

Martin, K. R., Johnson, T. P., \& Hughes, T. L. (2015). Using respondent driven sampling to recruit sexual minority women. Survey Practice, 8(2).

McCabe, S. E., Hughes, T. L., Bostwick, W., Morales, M., \& Boyd, C. J. (2012). Measurement of sexual identity in surveys: Implications for substance abuse research. Archives of Sexual Behavior, 41(3), 649-657. https://doi.org/10.1007/s10508-011-9768-7

McCabe, S. E., Hughes, T. L., Bostwick, W. B., West, B. T., $\&$ Boyd, C. J. (2009). Sexual orientation, substance use behaviors and substance dependence in the United States. Addiction, 104(8), 1333-1345. https://doi.org/10.1111/j.1360-0443.2009.02596.x
McKirnan, D. J., \& Peterson, P. L. (1989). Psychosocial and cultural factors in alcohol and drug abuse: An analysis of a homosexual community. Addictive Behaviors, 14(5), 555-563. $\quad$ https://doi.org/10.1016/03064603(89)90076-2

Mereish, E. H., Katz-Wise, S. L., \& Woulfe, J. (2017). We're here and we're queer: Sexual orientation and

sexual fluidity differences between bisexual and queer women. Journal of Bisexuality, 17(1), 125-139. https://doi.org/10.1080/15299716.2016.1217448

Michaels, S., Pineau, V., Reimer, B., Ganesh, N., \& Dennis, M. (2019). Test of a hybrid method of sampling the LGBT population: Web respondent driven sampling with seeds from a probability sample. Journal of Official Statistics, 35(4), 731-752. https://doi.org/10.2478/jos2019-0031

Midanik, L. T., \& Greenfield, T. K. (2008). Interactive voice response versus computer-assisted telephone interviewing (CATI) surveys and sensitive questions: The 2005 national alcohol survey. Journal of Studies on Alcohol and Drugs, 69(4), 580-588. https://doi.org/10.15288/jsad.2008.69.580

National Institute on Alcohol Abuse and Alcoholism. (2020). Drinking levels defined. https://www.niaaa.nih.gov/alcohol-health/overviewalcohol-consumption/moderate-binge-drinking

Ott, M. Q., Corliss, H. L., Wypij, D., Rosario, M., \& Austin, S. B. (2011). Stability and change in self-reported sexual orientation identity in young people: Application of mobility metrics. Archives of Sexual Behavior, 40(3), 519-532. https://doi.org/10.1007/s10508-010-9691-3

Parks, C. A. (1999). Lesbian social drinking: The role of alcohol in growing up and living as lesbian. Contemporary Drug Problems, 26(1), 75. https://doi.org/10.1177/009145099902600105

Pearlin, L. I., Schieman, S., Elena, M. F., \& Stephen, C. M. (2005). Stress, health, and the life course: Some conceptual perspectives. Journal of Health and Social Behavior, 46(2), 205-219. https://doi.org/210.1177/002214650504600206.

Riggle, E. D. B., Drabble, L., Veldhuis, C. B., Wootton, A., \& Hughes, T. L. (2018a). The impact of marriage equality on sexual minority women's relationships with their families of origin. Journal of Homosexuality, 65(9), 1190-1206. https://doi.org/10.1080/00918369.2017.1407611

Riggle, E. D. B., Drabble, L. A., Matthews, A. K., \& Veldhuis, C. B. (2020). First comes marriage, then comes the election: Macro-level event impacts on African American, Latina/x, and White sexual minority women. Sexuality Research \& Social Policy, 1-15. https://doi.org/10.1007/s13178-020-00435-z

Riggle, E. D. B., Rostosky, S. S., Drabble, L., Veldhuis, C. B., \& Hughes, T.L. (2018b). Sexual minority women's and gender-diverse individuals' hope and empowerment responses to the 2016 presidential election. Journal of GLBT Family Studies, 14(1-2), 152-173. https://doi.org/10.1080/1550428x.2017.1420853

Riley, B. B., Hughes, T. L., Wilsnack, S. C., Johnson, T. P., Benson, P., \& Aranda, F. (2017). Validating a hazardous drinking index in a sample of sexual minority women: Reliability, validity, and predictive accuracy. Substance 
Use and Misuse, 52(1), 43-51. https://doi.org/10.1080/10826084.2016.1214150

Sandfort, T. G., de Graaf, R., Bijl, R. V., \& Schnabel, P. (2001). Same-sex sexual behavior and psychiatric disorders: Findings from the Netherlands Mental Health Survey and Incidence Study (Nemesis). Archives of General Psychiatry, 58(1), 85-91. https://doi.org/10.1001/archpsyc.58.1.85

Sell, R. L., \& Becker, J. B. (2001). Sexual orientation data collection and progress toward Healthy People 2010. American Journal of Public Health, 91(6), 876-882. https://doi.org/10.2105/ajph.91.6.876

Skinner, W. F. (1994). The prevalence and demographic predictors of illicit and licit drug use among lesbians and gay men. American Journal of Public Health, 84(8), 1307-1310. https://doi.org/10.2105/ajph.84.8.1307

Suen, L. W., Lunn, M. R., Katuzny, K., Finn, S., Duncan, L., Sevelius, J., Flentje, A., Capriotti, M. R., Lubensky, M. E., Hunt, C., Weber, S., Bibbins-Domingo, K., \& Obedin-Maliver, J. (2020). What sexual and gender minority people want researchers to know about sexual orientation and gender identity questions: A qualitative study. Archives of Sexual Behavior, 49(7), 2301-2318. https://doi.org/10.1007/s10508-020-01810-y

Talley, A. E., Aranda, F., Hughes, T. L., Everett, B., \& Johnson, T. P. (2015). Longitudinal associations among discordant sexual orientation dimensions and hazardous drinking in a cohort of sexual minority women. Journal of Health and Social Behavior, 56(2), 225-245. https://doi.org/10.1177/0022146515582099

Talley, A. E., Gilbert, P. A., Mitchell, J., Goldbach, J., Marshall, B. D., \& Kaysen, D. (2016). Addressing gaps on risk and resilience factors for alcohol use outcomes in sexual and gender minority populations. Drug and Alcohol Review, 35(4), 484-493. https://doi.org/https://doi.org/10.1111/dar.12387

Talley, A., Veldhuis, C.B., Wilsnack, S.C., Wall, M., Shea, E., \& Hughes, T.L. (in review). The impact of adult role acquisitions and minority stressors on trajectories of hazardous drinking among sexual minority women drinkers.

Valanis, B. G., Bowen, D. J., Bassford, T., Whitlock, E., Charney, P., \& Carter, R. A. (2000). Sexual orientation and health: Comparisons in the Women's Health Initiative Sample. Archives of Family Medicine, 9(9), 843-853. https://doi.org/10.1001/archfami.9.9.843

Veldhuis, C.B., Talley, A.E., Hancock, D.W., Wilsnack, S.C., \& Hughes, T.L. (2017). Alcohol use, age, and selfrated mental and physical health in a community sample of lesbian and bisexual women. LGBT Health, 4(6), 419-426. https://doi.org/10.1089/lgbt.2017.0056

Veldhuis, C. B., Drabble, L., Riggle, E. D. B., Wootton, A. R., \& Hughes, T. L. (2018). "I fear for my safety, but want to show bravery for others": Violence and discrimination concerns among transgender and gendernonconforming individuals after the 2016 Presidential Election. Violence and Gender, 5(1), 26-36. https://doi.org/10.1089/vio.2017.0032

Wilsnack, R., \& Wilsnack, S. (2013). Gender and alcohol: Consumption and consequences. In P. Boyle, et al. (Eds.), Alcohol: Science, policy, and public health (pp. 153-160). Oxford University Press.
Wilsnack, R. W., Wilsnack, S. C., Kristjanson, A. F., \& Harris, T. R. (1998). Ten-year prediction of women's drinking behavior in a nationally representative sample. Womens Health Research on Gender, Behavior, and Policy, 4(3), 199-230.

Wilsnack, S. C., \& Wilsnack, R. W. (1995). Drinking and problem drinking in US women: Patterns and recent trends. In M. Galanter, et al. (Eds.), Recent developments in alcoholism, Vol. 12: Alcoholism and women. (pp. 2960). Plenum Press.

Wilsnack, S. C. (1991). Sexuality and Women's Drinking: Findings from a U.S. National Study. Alcohol Health and Research World, 15(2), 147. https://link.gale.com/apps/doc/A12490653/ITOF?u=col umbiau \&sid=ITOF\& $\mathrm{xid}=\mathrm{d} 5 \mathrm{db} 4099$

Wilsnack, S. C., Hughes, T. L., Johnson, T. P., Bostwick, W. B., Szalacha, L. A., Benson, P., Aranda, F., \& Kinnison, K. E. (2008). Drinking and drinking-related problems among heterosexual and sexual minority women. Journal of Studies on Alcohol and Drugs, 69(1), 129139. https://doi.org/10.15288/jsad.2008.69.129

Wilsnack, S. C., Klassen, A. D., Schur, B. E., \& Wilsnack, R. W. (1991). Predicting onset and chronicity of women's problem drinking: A five-year longitudinal analysis. American Journal of Public Health, 81(3), 114. https://doi.org/10.2105/ajph.81.3.305

Wilsnack, S. C., Klassen, A. D., \& Wilsnack, R. W. (1984). Drinking and reproductive dysfunction among women in a 1981 National Survey. Alcoholism: Clinical and Experimental Research, 8(5), 451-458. https://doi.org/10.1111/j.1530-0277.1984.tb05700.x

World Health Organization. (1994). Lexicon of Alcohol and Drug Terms. Published by the World Health Organization.

https://apps.who.int/iris/handle/10665/39461 